\title{
Epigenetics of Curcumin: A Gifted Dietary Therapeutics Compound
}

Gajendra Kumar Azad ${ }^{1,2}$ and Raghuvir S. Tomar ${ }^{1^{*}}$

${ }^{1}$ Laboratory of Chromatin Biology, Department of Biological Sciences, Indian Institute of Science Education and Research, Bhopal- 462023, India.

${ }^{2}$ Department of Genetics, Institute of Life Sciences, The Hebrew University of Jerusalem, Jerusalem 91904, Israel

${ }^{*}$ Corresponding author: Raghuvir S. Tomar, Associate Professor, Laboratory of Chromatin Biology, Department of Biological Sciences, Indian Institute of Science Education and Research, Bhopal- 462023, India, Phone: +91-755- 4092307; Fax: +91-755- 4092392; E-mail: rst@iiserb.ac.in

Received date: Nov 25, 2014, Accepted date: Dec 25 , 2014, Published date: Dec 30, 2014

Copyright: ( 2014 Azad GK, et al. This is an open-access article distributed under the terms of the Creative Commons Attribution License, which permits unrestricted use, distribution, and reproduction in any medium, provided the original author and source are credited.

\begin{abstract}
Purpose of review: Curcumin (CUR), an active polyphenol extracted from the rhizome of Curcuma longa, is a highly pleiotropic molecule having diverse biological activities. The purpose of this review is to present the facts that would assist to understand the Curcumin in regulation of epigenetics and future applications.

Recent findings: The recent growth in the understanding of the epigenetics is leading to a medical revolution that assures a new age of health and disease management. Compounds that have the potential to regulate epigenetics are of great pharmacological importance. Curcumin is one of the best-studied natural bioactive compounds known to interact with several molecular targets inside the cell and influences a range of biological processes. We have analyzed the findings of recent studies on effects of CUR on biological pathways. Accumulating studies suggest that CUR might be a promising agent to treat various human diseases that can occur due to alterations in epigenetics.
\end{abstract}

Summary: This review summarizes the actions of CUR on different chromatin modifiers, including, histone acetyl-transferases, histone deacetylases, and DNA methyl-transferases. Taking together, we have discussed the novel therapeutic potential of CUR, and we strongly believe that through future studies we will be able to effectively use CUR to improve the human health.

Keywords: Curcumin; Epigenetics; Drug-response; Histone modifications; Signaling pathways

\section{Introduction}

Chromatin is a dynamic structure and dynamicity is facilitated by altering the covalent modifications of histones [1]. This is carried out by a wide variety of chromatin modifying enzymes [2,3]. The combination of modifications ("marks") produced by chromatin modifying enzymes represents a code that controls downstream processes, such as, transcription, DNA repair, and apoptosis [4-7]. It is well established that mutations in chromatin-modifying machineries that disturb the spatial-temporal patterns of gene expression can contribute to the pathogenesis of human diseases. As a result, the scientific community has focused on identifying the small molecular inhibitors for many of the histone-modifying machineries and using them for targeted therapeutics. Hence, a number of bioactive dietary components are of particular interest in the field of epigenetics [8], including, curcumin (CUR).

Curcumin

(1,7-bis(4-hydroxy-3-methoxyphenyl)-1,6heptadiene-3,5-dione), chemical structure shown in figure 1 , is the major bright yellow color pigment extracted from turmeric [9]. Owing to its wide range of epigenetic targets, CUR has been extensively studied to better understand its diverse pharmacological activities and it has been used in several worldwide clinical trials [10]. This review summarizes the epigenetic targets of CUR and we discuss how CUR can be effective in treating various ailments by targeting epigenetic machineries and associated factors.<smiles>COc1cc(/C=C/C(=O)CC(=O)/C=C/c2ccc(O)c(OC)c2)ccc1O</smiles>

Figure 1: Chemical structure of Curcumin (1,7-bis(4-hydroxy-3methoxyphenyl)-1,6-heptadiene-3,5-dione

\section{Effect of curcumin on Epigenetics}

Over the past decade, knowledge regarding CUR biochemistry and its targeted pathways has grown tremendously, and it has been considered as a promising epigenetic modifier. Here, we will focus on how CUR alters post-translational modifications in histone proteins along with DNA methylation.

\section{Histone acetylation}

CUR attenuates histone acetylation levels causing histone hypoacetylation [11-14]. CUR is an inhibitor of p300/CREB-1 binding protein (CBP) HAT activity. It was established in vitro, that CUR covalently inhibited the acetylation of histones $\mathrm{H} 3$ and $\mathrm{H} 4$ by p300/CBP [15]. Moreover, the binding site on p300/CBP led to a conformational change, resulting in a reduction of binding efficiency 
of histones $\mathrm{H} 3$ and $\mathrm{H} 4$, and acetyl CoA [14,16], leading to a decrease in acetylation levels of these histones. Similarly, CUR inhibited the acetylation of histones and $\mathrm{p} 53$ in vivo through specific inhibition of p300/CBP in cervical cancer cells [17]. The inhibition of p300 by CUR also decreased acetylation on RelA protein causing defect in downstream nuclear processes [18]. Furthermore, CUR induced hypoacetylation of histones $\mathrm{H} 3$ and $\mathrm{H} 4$, leading to suppression of differentiation in astrocytes and has been implicated in determining stem cell fate through modulation of acetylation levels [19]. CUR not only affects the protein factors that are involved in histone acetylation but also regulates their expression. A study has revealed that, in mouse spermatids, the expression levels of several HATs, such as, CBP, Cdyl, and Myst4 [20-22] were significantly downregulated in response to CUR exposure [23]. The decrease in expression of HATs led to reduction in acetylation levels of histone $\mathrm{H} 4$ [23] in mouse spermatids.

\section{Histone deacetylation}

It has been demonstrated that CUR treatment causes a decrease in the mRNA expression of several HDACs including HDAC 1, 3, and 8 in Raji cells, thereby leading to significantly higher levels of histone $\mathrm{H} 4$ acetylation. Furthermore, western blots confirmed that CUR exposure significantly reduced the protein levels of $\operatorname{HDAC} 1,3$, and 8 in a dosedependent manner [24]. Although little is known about the molecular mechanisms behind the inhibitory action of CUR on HDACs, it has been suggested that CUR can modulate HDAC activity by regulating their expression. Reports suggest that in monocytes, CUR exposure causes decrease in the expression of HDAC2 [25]. Similarly in medulloblastoma cells, CUR blocks HDAC activity by decreasing HDAC4 expression [26]. However, through molecular docking experiments, it has been suggested that CUR can stably bind to human HDAC8 toward the entrance domain [27], and thereby, also affect the enzymatic function of HDACs.

\section{Histone phosphorylation}

It has been shown that CUR treatment increases the phosphorylation of histone $\mathrm{H} 3$ at Ser 10 residue in a dose-dependent manner [28] in mouse models. CUR exposure causes down-regulation of Aurora A transcript levels, which has been correlated with the reduction in histone $\mathrm{H} 3$ phospho-Ser10 levels [29] of human bladder cancer cells. Furthermore, CUR treatment has been proposed to alter the activity of histone phosphatases and/or kinases. We have also shown that CUR reduces the global levels of histone H3 acetylated at lysine-9 (H3K9ac) S10 phosphorylation in yeast cells [30]. There are reports suggesting that CUR can effectively target different signaling pathways, including MAPK, Akt, p53, androgen receptor (AR), Ras, and estrogen receptor (ER) pathways [31,32] in different human cell lines. Although not much is known about the effect of CUR on histone phosphorylation, we propose that because CUR interferes with various kinase pathways of the cells, it might regulate the phosphorylation state at several other residues of histone proteins [31,32].

\section{DNA methylation}

CUR has been shown to have the potential to inhibit DNMT1, leading to hypomethylation of various genes [33-35] in various human cell lines. It has been shown that CUR makes covalent interaction with DNMT1 and blocks the catalytic thiolate of C1226 of this enzyme to exert its inhibitory effect [35]. Another study demonstrated that CUR reduces global DNA methylation levels in a leukemia cell line at very low concentrations. CUR also inhibits enzymatic activity of M.Sss1 (methyltransferase Sss1, an analog of DNA methyltransferase I) in vitro [36,35]. Through genome wide studies, it has also been suggested that curcumin-induced changes in methylation occur only in a subset of partially-methylated genes [37] in colorectal cancer cells. CUR also reduces the hypermethylation of FANCF gene promoter, leading to an increase in the expression of FANCF in SiHa cells [39]. It was found that CUR causes the reversal of the methylation status of the first 5 $\mathrm{CpGs}$ in the upstream of $\mathrm{Nrf} 2$ gene with subsequent induction of $\mathrm{Nrf} 2$ [36]. CUR is also able to restore the expression of Nrf2 via promoter CpGs demethylation in TRAMP C1 prostate cancer cells treated at a concentration of $2.5 \mu \mathrm{M}$. Furthermore, another study revealed that CUR exposure led to demethylation of the first $14 \mathrm{CpG}$ sites of the CpG island in Neurog1 gene, which consequently led to the restoration of its expression in human prostate LNCaP cells [39].

\section{Effect of CUR on Various Biological Processes}

CUR can influence a wide range of molecular targets by either directly interacting with different molecules or indirectly modulating the signaling pathways. This section will illustrate the biological effects of CUR on various cellular pathways.

\section{DNA Repair}

It has been demonstrated that CUR can inhibit the DNA repair process in different model systems. CUR exposure causes impaired activation of ATR-Chk1 signaling [40] different cancer cell lines. Furthermore, the detailed study revealed that CUR could effectively induce histone hypoacetylation at the DNA double-strand break (DSB) sites by inhibiting specific HATs, thus inhibiting the recruitment of key repair factors at the DSB sites [40]. It was also demonstrated that CUR suppresses homologous recombination in DNA repair by inhibiting the expression of BRCA1 gene through impairing histone acetylation at its promoter [40]. We have also found that CUR activates DNA damage response in yeast cells [30]. Interestingly, Lu et al. discovered that CUR has the potential to cause DNA damage in combination with reducing the expression levels of DNA damage response genes, such as, BRCA1, ATM, ATR, 14-3-36, and DNA-PK, leading to impaired DNA damage response [41] in mouse-rat hybrid retina ganglion cells.

\section{Signaling pathways}

CUR displays promising pharmacological activities that are believed to be mediated through the regulation of cell signaling pathways, including, MAPK, JAK/STAT, Wnt/ $\beta$-catenin, and AMPK pathways [42-45] in human cells. Curcumin has been demonstrated to modulate the MAPK signaling pathway by decreasing p38 MAPK activation and reducing inflammation [46] in a murine model. CUR has been shown to inhibit the activation of JAK-STAT pathways through the inhibition of JAK1 and JAK2 phosphorylation in microglia cells [47]. Another study revealed that CUR can also inhibit the phosphorylation of Akt and the activation of mTOR (mammalian target of rapamycin) in human prostate cancer PC-3 cells [48]. In esophageal cancer cell lines, CUR has been shown to inhibit the activation of Notch-1 signaling by downregulating the expression levels of Notch-1 specific micro-RNAs, including, miR-21 and miR-34a [49]. Interestingly, CUR can activate AMPK pathway by down-regulating Erk1/2, p38, and COX-2 in colon cancer cells [50]. Furthermore, CUR exposure, together with radiotherapy, has been shown to enhance tumor cell death and reduce radio-resistance in mice with fibro-sarcomas through the inhibition of radiation-induced Erk and NF- $\mathrm{KB}$ expression [51]. 
Page 3 of 6

\section{Apoptosis}

CUR has been shown to reduce the expression of anti-apoptotic factors of the Bcl-2 family, including, Bcl-2 and Bcl-XL, as well as increase the expression of pro-apoptotic factors, such as, Bax, and procaspases-3, $-7,-8$, and -9 , leading to the induction of apoptosis [52] in various human cell lines. Furthermore, CUR can also induce apoptosis by mitochondrial pathway via cytochrome $\mathrm{C}$ release in different cancer cells including mantle cell lymphoma [53] and multiple myeloma cells [54]. CUR promotes apoptosis by inhibiting the Akt signaling pathways in cancer cells [55-57]. Another study has revealed that CUR induces apoptosis in various human melanoma cells through the Fas receptor/caspase-8 pathway [58]. CUR has also been shown to activate the TNF-related apoptosis-inducing ligand (TRAIL)-mediated apoptosis [59]. Due to the ability of CUR to target apoptotic pathway, it acts as an effective anti-cancer agents.

\section{Therapeutic Potential of Curcumin}

CUR has been consumed as a dietary supplement for centuries and has been widely used in Indian Ayurveda medicines [60]. Due to the diverse cellular targets, CUR is being used to treat as mentioned below.

\section{CUR is an effective agent against various human diseases}

CUR has been demonstrated to possess numerous pharmacological activities against a broad range of human diseases due to its antimicrobial $[61,62]$, anti-cancerous $[63,64]$, hepato-protective $[65,66]$, anti-thrombotic [67], cardio-protective [68,69], and anti-arthritic properties [70]. Furthermore, CUR is also protective against neurodegenerative diseases, including, Parkinson's and Alzheimer's diseases [71,72]. Additionally, CUR pretreatment has been associated with a considerable decline in liver fibrosis and injury in response to external stimuli $[73,74]$. CUR is effective in reducing blood glucose levels by increasing pancreatic $\beta$-cell function in diabetes mouse model [75]. The anti-diabetic effects of curcumin have also been attributed to its ability to decrease macrophage infiltration [76], increase antioxidant capacity, decrease IL-1 $\beta$, VEGF, and NF- $\kappa B$ activities $[77,78]$, and through enhancing the PPAR- $\Upsilon$ ligand-binding activity [79] in various mouse models of diabetes. Several studies demonstrated that CUR is effective against diabetes for example, in type 2 diabetic KK-A(y) mice; dietary turmeric extract reduced the blood glucose levels [79]. In diet-induced obesity mice and ob/ob male mice, dietary curcumin (3\%) for 6 weeks improves glycemic status and insulin sensitivity [76]. In another mouse diabetes model, dietary curcumin $(0.2 \%)$ for 6 weeks was beneficial in improving glucose homeostasis and insulin resistance [80].

The high efficacy of CUR in inhibiting cell proliferation and inducing cell death in different cancer cell lines makes it a promising anti-cancer drug [81-83]. Several studies conducted on patients with cancer, show that CUR has anti-proliferative and pro-apoptotic effects on pancreatic carcinoma, liver carcinoma, and leukemia $[83,84]$. Aberrant p300/CBP activity has been implicated in cancer progression and CUR inhibits p300/CBP HAT activity [85]. Moreover, CUR also reduces the cardiac ischemia-reperfusion injury by decreasing the expression of key molecules such as toll-like receptor 2 (TLR2), MCP-1, and CD68 [86]. Genome wide microarray study indicated that CUR mediates differential expression of genes involved in the protection of cardiac hypertrophy and inflammation [87-89].

\section{Anti-parasitic effect of Curcumin}

CUR exhibits anti-parasitic effect through modulating cellular histone acetylation levels [90]. One study demonstrated that CUR specifically hampers the in vivo PfGCN5 HAT activity in Plasmodium falciparum [90]. It has been observed that CUR also regulates the defense pathways of Salmonella typhimurium [91]. CUR strongly inhibits the proliferation of Helicobacter pylori that is a causative agent of gastric ulcers and also implicated in gastric cancers. CUR also effectively blocks the $\mathrm{H}$. pylori-induced mitogenic response, leading to the inhibition of NF- $\kappa \mathrm{B}$ activation and subsequent downstream processes [92]. An interesting study demonstrated that the deleterious effects of the fecal parasite, Eimeria maxima, were significantly reduced by CUR in chickens [93]. Another animal study showed that the dermatophyte- and fungi-infected guinea pigs were relieved from disease symptoms upon CUR treatment [94]. Furthermore, CUR also possesses anti-leishmanial activity by exhibiting cytotoxic effect on its causative agent Leishmania donovani $[95,96]$.

\section{CUR in Clinical Trials}

Since CUR possesses promising therapeutic potential [97,98], several clinical trials have already been conducted to investigate its effects on the prevention and/or treatment of various diseases [99-102]. There was no significant treatment-related toxicity was observed in doses up to $8 \mathrm{~g}$ /day for 3 months $[103,104]$ on human patients. CUR treatment also effectively revert the general health status of patients with colorectal cancer [105]. In several human clinical trials, CUR has been administered in combination with other agents. For example, when curcumin was used with piperine, the pain was significantly reduced [106]. Similarly, CUR sensitized the effect of gemcitabine in gemcitabine-resistant pancreatic cancer when used at 8 g/day in combination with gemcitabine [107]. Furthermore, CUR increased the efficacy of prednisone in patients with ulcerative colitis [107] and ultraviolet B against skin disorder to yield significant improvements [108]. Interestingly, one clinical trial revealed that CUR was very effective against type 2 diabetes treatment [109].

\section{Future directions and conclusions}

Exploring epigenetic properties of CUR in humans will potentially enhance our understanding of its medicinal values. CUR also shows reduced bioavailability issue. Hence, it will be interesting to discover and characterize novel CUR derivatives that are more stable or more readily absorbed upon administration. For example, curcuminencapsulated/curcumin-derived exosomes are more stable and can be directed towards target sites. Moreover, CUR can directly bind and alter multiple cell signaling cascades, which can be harnessed to combat selected pathologies including cancer. Future research in this area will provide further insights into the use of CUR and its analogues as efficacious agents to target different diseases. CUR is also shown to be effective on age-related symptoms. Interestingly, CUR has been reported to enhance the lifespan in Caenorhabditis elegans and Drosophila spp., but its efficacy on humans warrants future exploration. The efficacy of different drugs has been shown to improve significantly when they were administered in combination with CUR. Hence, new drug combinations with CUR can be explored in the near future. Existing reports strongly suggest that CUR is an effective therapeutic agent but its efficacy on animals and humans are not completely understood. Hence, it is essential to learn more about the pharmacodynamics and pharmacokinetics of CUR in the near future to assess its medicinal values. 


\section{Conclusions}

In summary, we have reviewed recent experimental evidences regarding the biology of CUR. It has been clearly demonstrated that CUR targets various signaling pathways that eventually affects epigenetics. This property of CUR has motivated researchers for developing therapeutic strategies by targeting different epigenetic factors including HDACs, HATs, and DNMTs. Further examination of CUR as an epigenetic agent is required to fully explore its potential for treating various diseases including cancer. We believe that continuous research on CUR and well-controlled human studies will address the biology as well as the therapeutic potential of this micronutrient.

\section{Acknowledgements}

We are thankful to all members of the Laboratory of Chromatin Biology for critical readings, discussions, or ideas for manuscript preparation.

\section{Financial Support and Sponsorship}

This research work was supported by the Department of Biotechnology (DBT) and Council of Scientific and Industrial Research (CSIR), Govt. of India to RST. CSIR is acknowledged for fellowship support to GKA.

\section{References}

1. Kouzarides $\mathrm{T}$ (2007) Chromatin modifications and their function. Cell 128: 693-705.

2. Shilatifard A (2006) Chromatin modifications by methylation and ubiquitination: implications in the regulation of gene expression. Annu Rev Biochem 75: 243-269.

3. Barth TK, Imhof A (2010) Fast signals and slow marks: the dynamics of histone modifications. Trends Biochem Sci 35: 618-626.

4. Hübner MR, Eckersley-Maslin MA, Spector DL (2013) Chromatin organization and transcriptional regulation. Curr Opin Genet Dev 23: 89-95.

5. Groth A, Rocha W, Verreault A, Almouzni G (2007) Chromatin challenges during DNA replication and repair. Cell 128: 721-733.

6. Yang H, Ren Q, Zhang Z (2006) Chromosome or chromatin condensation leads to meiosis or apoptosis in stationary yeast (Saccharomyces cerevisiae) cells. FEMS Yeast Res 6: 1254-1263.

7. Azad GK, Tomar RS (2014) Proteolytic clipping of histone tails: the emerging role of histone proteases in regulation of various biological processes. Mol Biol Rep 41: 2717-2730.

8. Reuter S, Gupta SC, Park B, Goel A, Aggarwal BB (2011) Epigenetic changes induced by curcumin and other natural compounds. Genes Nutr 6: 93-108.

9. Sharma RA, Gescher AJ, Steward WP (2005) Curcumin: the story so far. Eur J Cancer 41: 1955-1968.

10. Reuter S, Eifes S, Dicato M, Aggarwal BB, Diederich M (2008) Modulation of anti-apoptotic and survival pathways by curcumin as a strategy to induce apoptosis in cancer cells. Biochem Pharmacol 76: 1340-1351.

11. Taniura H, Sng JC, Yoneda Y (2006) Histone modifications in status epilepticus induced by kainate. Histol Histopathol 21: 785-791.

12. Sng JC, Taniura H, Yoneda Y (2006) Histone modifications in kainateinduced status epilepticus. Eur J Neurosci 23: 1269-1282.

13. Kang J, Chen J, Shi Y, Jia J, Zhang Y (2005) Curcumin-induced histone hypoacetylation: the role of reactive oxygen species. Biochem Pharmacol 69: 1205-1213.
14. Marcu MG, Jung YJ, Lee S, Chung EJ, Lee MJ, et al. (2006) Curcumin is an inhibitor of p300 histone acetylatransferase. Med Chem 2: 169-174.

15. Morimoto T, Sunagawa Y, Kawamura T, Takaya T, Wada H, et al. (2008) The dietary compound curcumin inhibits p300 histone acetyltransferase activity and prevents heart failure in rats. The Journal of clinical investigation $118: 868-878$.

16. Piwocka K, ZabÅ,ocki K, Wieckowski MR, Skierski J, Feiga I, et al. (1999) A novel apoptosis-like pathway, independent of mitochondria and caspases, induced by curcumin in human lymphoblastoid $\mathrm{T}$ (Jurkat) cells. Exp Cell Res 249: 299-307.

17. Bielak-Zmijewska A, Koronkiewicz M, Skierski J, Piwocka K, Radziszewska E, et al. (2000) Effect of curcumin on the apoptosis of rodent and human nonproliferating and proliferating lymphoid cells. Nutr Cancer 38: 131-138.

18. Chen Lf, Fischle W, Verdin E, Greene WC (2001) Duration of nuclear NF-kappaB action regulated by reversible acetylation. Science 293: 1653-1657.

19. Kang SK, Cha SH, Jeon HG (2006) Curcumin-induced histone hypoacetylation enhances caspase-3-dependent glioma cell death and neurogenesis of neural progenitor cells. Stem Cells Dev 15: 165-174.

20. Lahn BT, Tang ZL, Zhou J, Barndt RJ, Parvinen M, et al. (2002) Previously uncharacterized histone acetyltransferases implicated in mammalian spermatogenesis. Proceedings of the National Academy of Sciences of the United States of America: 8707-8712.

21. Caron C, Pivot-Pajot C, van Grunsven LA, Col E, Lestrat C, et al. (2003) Cdyl: a new transcriptional co-repressor. EMBO Rep 4: 877-882.

22. McGraw S, Morin G, Vigneault C, Leclerc P, Sirard MA (2007) Investigation of MYST4 histone acetyltransferase and its involvement in mammalian gametogenesis. BMC Dev Biol 7: 123.

23. Xia X, Cai H, Qin S, Xu C (2012) Histone acetylase inhibitor curcumin impairs mouse spermiogenesis-an in vitro study. PLoS One 7: e48673.

24. Liu HL, Chen Y, Cui GH, Zhou JF (2005) Curcumin, a potent anti-tumor reagent, is a novel histone deacetylase inhibitor regulating B-NHL cell line Raji proliferation. Acta Pharmacol Sin 26: 603-609.

25. Meja KK, Rajendrasozhan S, Adenuga D, Biswas SK, Sundar IK, et al. (2008) Curcumin restores corticosteroid function in monocytes exposed to oxidants by maintaining HDAC2. Am J Respir Cell Mol Biol 39: 312-323.

26. Lee SJ, Krauthauser C, Maduskuie V, Fawcett PT, Olson JM, et al. (2011) Curcumin-induced HDAC inhibition and attenuation of medulloblastoma growth in vitro and in vivo. BMC Cancer 11: 144.

27. Bora-Tatar G, Dayangac-Erden D, Demir AS, Dalkara S, Yelekci K, et al (2009). Molecular modifications on carboxylic acid derivatives as potent histone deacetylase inhibitors: Activity and docking studies. Bioorganic \& medicinal chemistry $17: 5219-5228$.

28. Tikoo K, Meena RL, Kabra DG, Gaikwad AB (2008) Change in posttranslational modifications of histone $\mathrm{H} 3$, heat-shock protein-27 and MAP kinase p38 expression by curcumin in streptozotocin-induced type I diabetic nephropathy. British journal of pharmacology153: 1225-1231.

29. Liu HS, Ke CS, Cheng HC, Huang CY, Su CL (2011) Curcumin-induced mitotic spindle defect and cell cycle arrest in human bladder cancer cells occurs partly through inhibition of aurora A. Molecular pharmacology 80: 638-646

30. Azad GK, Singh V, Golla U, Tomar RS (2013) Depletion of cellular iron by curcumin leads to alteration in histone acetylation and degradation of Smllp in Saccharomyces cerevisiae. PLoS One 8: e59003.

31. Ranjan D, Chen C, Johnston TD, Jeon H, Nagabhushan M (2004) Curcumin inhibits mitogen stimulated lymphocyte proliferation, NFkappaB activation, and IL-2 signaling. The Journal of surgical research 121: 171-177.

32. Wu LX, Xu JH, Wu GH, Chen YZ (2003) Inhibitory effect of curcumin on proliferation of K562 cells involves down-regulation of p210(bcr/abl) initiated Ras signal transduction pathway. Acta Pharmacol Sin 24: 1155-1160. 
33. Jha AK, Nikbakht M, Parashar G, Shrivastava A, Capalash N, et al. (2010) Reversal of hypermethylation and reactivation of the RARI ${ }^{2} 2$ gene by natural compounds in cervical cancer cell lines. Folia Biol (Praha) 56: 195-200.

34. Kuck D, Singh N, Lyko F, Medina-Franco JL (2010) Novel and selective DNA methyltransferase inhibitors: Docking-based virtual screening and experimental evaluation. Bioorganic \& medicinal chemistry 18: 822-829.

35. Liu Z, Xie Z, Jones W, Pavlovicz RE, Liu S, et al. (2009) Curcumin is a potent DNA hypomethylation agent. Bioorg Med Chem Lett 19: 706-709.

36. Khor TO, Huang Y, Wu TY, Shu L, Lee J, et al. (2011) Pharmacodynamics of curcumin as DNA hypomethylation agent in restoring the expression of $\mathrm{Nrf} 2$ via promoter CpGs demethylation. Biochem Pharmacol 82: 1073-1078.

37. Link A, Balaguer F, Shen Y, Lozano JJ, Leung HC, et al. (2013) Curcumin modulates DNA methylation in colorectal cancer cells. PLoS One 8: e57709.

38. Parashar G, Parashar NC, Capalash N (2012) Curcumin causes promoter hypomethylation and increased expression of FANCF gene in SiHa cell line. Mol Cell Biochem 365: 29-35.

39. Shu L, Khor TO, Lee JH, Boyanapalli SS, Huang Y, et al. (2011) Epigenetic $\mathrm{CpG}$ demethylation of the promoter and reactivation of the expression of Neurog1 by curcumin in prostate LNCaP cells. AAPS J 13: 606-614.

40. Ogiwara H, Ui A, Shiotani B, Zou L, Yasui A, et al. (2013) Curcumin suppresses multiple DNA damage response pathways and has potency as a sensitizer to PARP inhibitor. Carcinogenesis 34: 2486-2497.

41. Lu HF, Yang JS, Lai KC, Hsu SC, Hsueh SC, et al. (2009) Curcumininduced DNA damage and inhibited DNA repair genes expressions in mouse-rat hybrid retina ganglion cells (N18). Neurochem Res 34: 1491-1497.

42. Shieh SY, Ikeda M, Taya Y, Prives C (1997) DNA damage-induced phosphorylation of $\mathrm{p} 53$ alleviates inhibition by MDM2. Cell 91: 325-334.

43. Pan W, Yang H, Cao C, Song X, Wallin B, et al. (2008) AMPK mediates curcumin-induced cell death in CaOV3 ovarian cancer cells. Oncol Rep 20: 1553-1559.

44. Duan W, Yang Y, Yan J, Yu S, Liu J, et al. (2012) The effects of curcumin post-treatment against myocardial ischemia and reperfusion by activation of the JAK2/STAT3 signaling pathway. Basic Res Cardiol 107: 263.

45. Prasad CP, Rath G, Mathur S, Bhatnagar D, Ralhan R (2009) Potent growth suppressive activity of curcumin in human breast cancer cells Modulation of Wnt/beta-catenin signaling. Chemico-biological interactions 181: 263-271.

46. Salh B, Assi K, Templeman V, Parhar K, Owen D, et al. (2003) Curcumin attenuates DNB-induced murine colitis. Am J Physiol Gastrointest Liver Physiol 285: G235-243.

47. Kim HY, Park EJ, Joe EH, Jou I (2003) Curcumin suppresses Janus kinase-STAT inflammatory signaling through activation of Src homology 2 domain-containing tyrosine phosphatase 2 in brain microglia. J Immunol.171: 6072-6079.

48. Yu S, Shen G, Khor TO, Kim JH, Kong AN (2008) Curcumin inhibits Akt/mammalian target of rapamycin signaling through protein phosphatase-dependent mechanism. Molecular cancer therapeutics 7: 2609-2620.

49. Subramaniam D, Ponnurangam S, Ramamoorthy P, Standing D Battafarano RJ, et al. (2012) Curcumin induces cell death in esophageal cancer cells through modulating Notch signaling. PLoS One 7: e30590.

50. Lee YK, Lee WS, Hwang JT, Kwon DY, Surh YJ, et al (2009) Curcumin exerts antidifferentiation effect through AMPKalpha-PPAR-gamma in 3T3-L1 adipocytes and antiproliferatory effect through AMPKalphaCOX-2 in cancer cells. Journal of agricultural and food chemistry 57(1): 305-310.

51. Kumar Mitra A, Krishna M (2004) In vivo modulation of signaling factors involved in cell survival. J Radiat Res 45: 491-495.
52. Aggarwal BB (2004) Nuclear factor-kappaB: the enemy within. Cancer Cell 6: 203-208.

53. Shishodia S, Amin HM, Lai R, Aggarwal BB (2005) Curcumin (diferuloylmethane) inhibits constitutive NF-kappaB activation, induces G1/S arrest, suppresses proliferation, and induces apoptosis in mantle cell lymphoma. Biochemical pharmacology 70: 700-713.

54. Bharti AC, Donato N, Singh S, Aggarwal BB (2003) Curcumin (diferuloylmethane) down-regulates the constitutive activation of nuclear factor-kappa B and IkappaBalpha kinase in human multiple myeloma cells, leading to suppression of proliferation and induction of apoptosis. Blood 101: 1053-1062.

55. Squires MS, Hudson EA, Howells L, Sale S, Houghton CE, et al. (2003) Relevance of mitogen activated protein kinase (MAPK) and phosphotidylinositol-3-kinase/protein kinase B (PI3K/PKB) pathways to induction of apoptosis by curcumin in breast cells. Biochem Pharmacol 65: 361-376.

56. Woo JH, Kim YH, Choi YJ, Kim DG, Lee KS, et al. (2003) Molecular mechanisms of curcumin-induced cytotoxicity: induction of apoptosis through generation of reactive oxygen species, down-regulation of $\mathrm{Bcl}$ $\mathrm{XL}$ and IAP, the release of cytochrome $\mathrm{c}$ and inhibition of Akt. Carcinogenesis 24: 1199-1208.

57. Chaudhary LR, Hruska KA (2003) Inhibition of cell survival signal protein kinase B/Akt by curcumin in human prostate cancer cells. J Cell Biochem 89: 1-5.

58. Bush JA1, Cheung KJ Jr, Li G (2001) Curcumin induces apoptosis in human melanoma cells through a Fas receptor/caspase- 8 pathway independent of p53. Exp Cell Res 271: 305-314.

59. Jung EM, Park JW, Choi KS, Lee HI, Lee KS, et al. (2006) Curcumin sensitizes tumor necrosis factor-related apoptosis-inducing ligand (TRAIL)-mediated apoptosis through CHOP-independent DR5 upregulation Carcinogenesis 27: 2008-2017.

60. Aggarwal BB, Sundaram C, Malani N, Ichikawa H (2007) Curcumin: the Indian solid gold. Adv Exp Med Biol 595: 1-75.

61. Reddy RC, Vatsala PG, Keshamouni VG, Padmanaban G, Rangarajan PN (2005) Curcumin for malaria therapy. Biochem Biophys Res Commun 326: $472-474$.

62. Na HS, Cha MH, Oh DR, Cho CW, Rhee JH, et al. (2011) Protective mechanism of curcumin against Vibrio vulnificus infection. FEMS Immunol Med Microbiol 63: 355-362.

63. Basnet P, Skalko-Basnet N (2011) Curcumin: an anti-inflammatory molecule from a curry spice on the path to cancer treatment. Molecules 16: 4567-4598.

64. Darvesh AS, Aggarwal BB, Bishayee A (2012) Curcumin and liver cancer: a review. Curr Pharm Biotechnol 13: 218-228.

65. Singh R, Sharma P (2011) Hepatoprotective Effect of Curcumin on Lindane-induced Oxidative Stress in Male Wistar Rats. Toxicol Int 18: 124-129.

66. Girish C, Pradhan SC (2012) Hepatoprotective activities of picroliv, curcumin, and ellagic acid compared to silymarin on carbontetrachloride-induced liver toxicity in mice. Journal of pharmacology \& pharmacotherapeutics: 149-155.

67. Srivastava R, Dikshit M, Srimal RC, Dhawan BN (1985) Anti-thrombotic effect of curcumin. Thromb Res 40: 413-417.

68. Miriyala S, Panchatcharam M, Rengarajulu P (2007) Cardioprotective effects of curcumin. Adv Exp Med Biol 595: 359-377.

69. Izem-Meziane M, Djerdjouri B, Rimbaud S, Caffin F, Fortin D, et al. (2012) Catecholamine-induced cardiac mitochondrial dysfunction and mPTP opening: protective effect of curcumin. American journal of physiology Heart and circulatory physiology 302: H665-H674.

70. Chandran B, Goel A (2012) A randomized, pilot study to assess the efficacy and safety of curcumin in patients with active rheumatoid arthritis. Phytother Res 26: 1719-1725.

71. Begum AN, Jones MR, Lim GP, Morihara T, Kim P, et al. (2008) Curcumin structure-function, bioavailability, and efficacy in models of 
neuroinflammation and Alzheimer's disease. J Pharmacol Exp Ther 326: 196-208.

72. Pandey N, Strider J, Nolan WC, Yan SX, Galvin JE (2008) Curcumin inhibits aggregation of alpha-synuclein. Acta Neuropathol 115: 479-489.

73. Tu CT, Han B, Yao QY, Zhang YA, Liu HC, et al. (2012) Curcumin attenuates Concanavalin A-induced liver injury in mice by inhibition of Toll-like receptor (TLR) 2, TLR4 and TLR9 expression. Int Immunopharmacol 12: 151-157.

74. Tu CT, Yao QY, Xu BL, Wang JY, Zhou CH, et al. (2012) Protective effects of curcumin against hepatic fibrosis induced by carbon tetrachloride: modulation of high-mobility group box 1, Toll-like receptor 4 and 2 expression. Food and chemical toxicology 50: 3343-3351.

75. Zhou H, Beevers CS, Huang S (2011) The targets of curcumin. Curr Drug Targets 12: 332-347.

76. Weisberg SP, Leibel R, Tortoriello DV (2008) Dietary curcumin significantly improves obesity-associated inflammation and diabetes in mouse models of diabesity. Endocrinology 149: 3549-3558

77. Barzegar A, Moosavi-Movahedi AA (2011) Intracellular ROS protection efficiency and free radical-scavenging activity of curcumin. PLoS One 6: e26012.

78. Kowluru RA, Kanwar M (2007) Effects of curcumin on retinal oxidative stress and inflammation in diabetes. Nutr Metab (Lond) 4: 8.

79. Nishiyama T, Mae T, Kishida H, Tsukagawa M, Mimaki Y, et al. (2005) Curcuminoids and sesquiterpenoids in turmeric (Curcuma longa L.) suppress an increase in blood glucose level in type 2 diabetic KK-Ay mice. J Agric Food Chem 53: 959-963.

80. Seo KI, Choi MS, Jung UJ, Kim HJ, Yeo J, et al. (2008) Effect of curcumin supplementation on blood glucose, plasma insulin, and glucose homeostasis related enzyme activities in diabetic $\mathrm{db} / \mathrm{db}$ mice. Molecular nutrition \& food research 52: 995-1004

81. Bielak-Mijewska A, Piwocka K, Magalska A, Sikora E (2004) Pglycoprotein expression does not change the apoptotic pathway induced by curcumin in HL-60 cells. Cancer Chemother Pharmacol 53: 179-185.

82. Bielak-Zmijewska A, Sikora-Polaczek M, Nieznanski K, Mosieniak G, Kolano A, et al. (2010) Curcumin disrupts meiotic and mitotic divisions via spindle impairment and inhibition of CDK1 activity. Cell Prolif 43: 354-364.

83. Aggarwal BB, Kumar A, Bharti AC (2003) Anticancer potential of curcumin: preclinical and clinical studies. Anticancer Res 23:363-398.

84. Leu TH, Maa MC (2002) The molecular mechanisms for the antitumorigenic effect of curcumin. Curr Med Chem Anticancer Agents 2: 357-370.

85. Balasubramanyam K, Varier RA, Altaf M, Swaminathan V, Siddappa NB, et al. (2004) Curcumin, a novel p300/CREB-binding protein-specific inhibitor of acetyltransferase, represses the acetylation of histone/ nonhistone proteins and histone acetyltransferase-dependent chromatin transcription. The Journal of biological chemistry 279: 51163-51171

86. Kim YS, Kwon JS, Cho YK, Jeong MH, Cho JG, et al. (2012) Curcumin reduces the cardiac ischemia-reperfusion injury: involvement of the tolllike receptor 2 in cardiomyocytes. J Nutr Biochem 23: 1514-1523.

87. Morimoto T, Sunagawa Y, Fujita M, Hasegawa K (2010) Novel heart failure therapy targeting transcriptional pathway in cardiomyocytes by a natural compound, curcumin. Circulation journal 74: 1059-1066

88. Hong D, Zeng X, Xu W, Ma J, Tong Y, et al. (2010) Altered profiles of gene expression in curcumin-treated rats with experimentally induced myocardial infarction. Pharmacological research 61: 142-148.

89. Li HL, Liu C, de Couto G, Ouzounian M, Sun M, et al. (2008) Curcumin prevents and reverses murine cardiac hypertrophy. J Clin Invest 118: 879-893.
90. Cui L, Miao J (2007) Cytotoxic effect of curcumin on malaria parasite Plasmodium falciparum: inhibition of histone acetylation and generation of reactive oxygen species. Antimicrob Agents Chemother 51: 488-494.

91. Marathe SA, Ray S, Chakravortty D (2010) Curcumin increases the pathogenicity of Salmonella enterica serovar Typhimurium in murine model. PLoS One 5: e11511.

92. De R, Kundu P, Swarnakar S, Ramamurthy T, Chowdhury A, et al. (2009) Antimicrobial activity of curcumin against Helicobacter pylori isolates from India and during infections in mice. Antimicrob Agents Chemother 53: 1592-1597

93. Kim DK, Lillehoj HS, Lee SH, Jang SI, Lillehoj EP, et al. (2013) Dietary Curcuma longa enhances resistance against Eimeria maxima and Eimeria tenella infections in chickens. Poult Sci 92: 2635-2643.

94. Apisariyakul A, Vanittanakom N, Buddhasukh D (1995) Antifungal activity of turmeric oil extracted from Curcuma longa (Zingiberaceae). J Ethnopharmacol 49: 163-169.

95. Das R, Roy A, Dutta N, Majumder HK (2008) Reactive oxygen species and imbalance of calcium homeostasis contributes to curcumin induced programmed cell death in Leishmania donovani. Apoptosis 13: 867-882.

96. Chan MM, Adapala NS, Fong D (2005) Curcumin overcomes the inhibitory effect of nitric oxide on Leishmania. Parasitol Res 96: 49-56.

97. Wang L, Tang Y, Cole PA, Marmorstein R (2008) Structure and chemistry of the p300/CBP and Rtt109 histone acetyltransferases: implications for histone acetyltransferase evolution and function. Current opinion in structural biology. 18: 741-747.

98. Dekker FJ, Haisma HJ (2009) Histone acetyl transferases as emerging drug targets. Drug Discov Today 14: 942-948.

99. Gupta SC, Kismali G, Aggarwal BB (2013) Curcumin, a component of turmeric: from farm to pharmacy. Biofactors 39: 2-13.

100. Shehzad A, Lee J, Lee YS (2013) Curcumin in various cancers. Biofactors 39: 56-68.

101. Monroy A, Lithgow GJ, Alavez S (2013) Curcumin and neurodegenerative diseases. Biofactors 39: 122-132.

102. Vera-Ramirez L1, Pérez-Lopez P, Varela-Lopez A, Ramirez-Tortosa M, Battino M, et al. (2013) Curcumin and liver disease. Biofactors 39: $88-100$.

103. Dhillon N, Aggarwal BB, Newman RA, Wolff RA, Kunnumakkara AB, et al. (2008) Phase II trial of curcumin in patients with advanced pancreatic cancer. Clinical cancer research : an official journal of the American Association for Cancer Research: 4491-4499.

104. Kanai M, Yoshimura K, Asada M, Imaizumi A, Suzuki C, et al. (2011) A phase I/II study of gemcitabine-based chemotherapy plus curcumin for patients with gemcitabine-resistant pancreatic cancer. Cancer chemotherapy and pharmacology: 157-164.

105. He ZY, Shi CB, Wen H, Li FL, Wang BL, et al. (2011) Upregulation of p53 expression in patients with colorectal cancer by administration of curcumin. Cancer Invest 29: 208-213.

106. Durgaprasad S, Pai CG, Vasanthkumar, Alvres JF, Namitha S (2005) A pilot study of the antioxidant effect of curcumin in tropical pancreatitis. Indian J Med Res 122: 315-318.

107. Lahiff C, Moss AC (2011) Curcumin for clinical and endoscopic remission in ulcerative colitis. Inflamm Bowel Dis 17: E66.

108. Asawanonda P, Klahan SO (2010) Tetrahydrocurcuminoid cream plus targeted narrowband UVB phototherapy for vitiligo: a preliminary randomized controlled study. Photomed Laser Surg 28: 679-684.

109. Usharani P, Mateen AA, Naidu MU, Raju YS, Chandra N (2008) Effect of NCB-02, atorvastatin and placebo on endothelial function, oxidative stress and inflammatory markers in patients with type 2 diabetes mellitus: a randomized, parallel-group, placebo-controlled, 8-week study. Drugs in R\&D 9: 243-250 